Recebido em: 12 de março de 2019

Aprovado em: 05 de julho de 2019

Sistema de Avaliação: Double Blind Review

RPR |a. 16 |n. 3|p. 98-109| set./dez. 2019

DOI: https://doi.org/10.25112/rpr.v3i0.2008

\title{
EDUCAR PARA O FIM DO EMPREGO?
}

\section{EDUCATE FOR THE END OF EMPLOYMENT?}

\section{Cleber Cristiano Prodanov}

Doutor em História Social pela Universidade de São Paulo. Professor na Universidade Feevale.

E-mail: prodanov@feevale.br

\section{Gabriel Grabowski}

Doutor em Educação pela Universidade Federal do Rio Grande do Sul. Professor na Universidade Feevale.

E-mail: gabrielg@feevale.br 


\section{RESUMO}

Este artigo procura analisar algumas das transformações econômicas, científicas e tecnológicas que impactam os sistemas de trabalho, produção, educação e formação profissional, uma vez que nada é imune às transformações em curso em nosso século. As relações de emprego e os projetos de carreira profissional estão em profundas mudanças, deixando de serem trajetórias e carreiras profissionais estáveis e duradouras e configurando-se em relações intermitentes, temporárias e por demandas. Nesta perspectiva, não é o trabalho, enquanto relação de produção da sobrevivência humana que está ameaçado, mas os empregos que estão em processo de precarização e/ou extinção. Este artigo propõe uma reflexão sobre as teses que anunciam o fim do emprego, no contexto atual, a partir das transformações em movimento e seus impactos no processo de educação. Metodologicamente, trata-se de um estudo qualitativo e quantitativo, ancorado em fontes bibliográficas e documentais, indicadores de economia e de mercado do trabalho, referenciado em pensadores da sociologia do trabalho e da educação contemporânea. Conceitualmente, esta reflexão implica discernirmos e diferenciarmos as noções de emprego, formação profissional e educação, no contexto histórico que estamos vivenciando.

Palavras-chave: Educação. Trabalho. Tecnologias. Futuro do Emprego.

\section{ABSTRACT}

This article analyzes some of the economic, scientific, and technological transformations that impact labor, production, education, and professional training systems, since nothing is immune to the ongoing transformations in our century. Employment relationships and professional career projects are undergoing profound changes, moving from stable and lasting professional careers to intermittent, temporary and demanding relationships. In this perspective, it is not work as a production relation of human survival that is threatened, but jobs that are in the process of precariousness or extinction. This article proposes a reflection on the theses that announce the end of employment, in the current context, from changes in movement and their impacts on the education process. Methodologically, it is a qualitative and quantitative study, anchored in bibliographic and documentary sources, labor market and economy indicators, referenced with intellectuals in the sociology of work and contemporary education. Conceptually, this reflection implies discerning and differentiating the notions of employment, professional training and education in the historical context we are experiencing.

Keywords: Education. Work. Technologies. Future of Employment. 


\section{INTRODUÇÃO}

Já há algum tempo que formadores de opinião e especialistas têm difundido a ideia de que "no futuro não existirão empregos, mas empreedimentos e empreededores". Tal visão de um futuro avassalador nas relações de trabalho, que ceifará milhões de postos de emprego, que se tornarão irrecuperáveis, parece ser uma tendência real em curso e que impactará o processo de educação e formação profissional. Embora não se acredite em um determinismo a priori, a tendência mundial tem apontado para profundas mudanças nas relações de empregos e salários, bem como entre trabalho e educação.

No livro 21 lições para o século 21, Yuval Noah Harari (2018) diz que não temos ideia de como será o mercado de trabalho em 2050, porém, sabemos que o aprendizado das máquinas e a robótica virão mudar quase todas as modalidades de trabalho - desde produção de iogurte até o ensino de ioga. Ao considerar o que disseram e continuam a dizer numerosos filósofos e cientistas sociais, nas últimas décadas, paira uma dúvida: podemos dizer adeus ao trabalho?

Este artigo propõe-se a debater sobre os rumos da economia e do mercado de trabalho, visto que tal abordagem tem sido muito difusa, com análises que apresentam grandes variações ${ }^{2}$. Entretanto, o fenômeno social é que, a partir da década de 1980, o mercado de trabalho inverteu o sentido dos principais indicadores de comportamento, dando origem a um movimento de desestruturação do mercado de trabalho e a um crescimento, cada vez maior, do desemprego aberto, cuja taxa mais que quintuplicou, passando de 2,8\%, em 1980, para 15\%, em 2000. Este processo foi acompanhado, também, pela presença do desassalariamento, que tinha dois a cada três ocupados em 1980 e retrocedeu para $58 \%$ em meados de 2000.

Consoante Pochmann (2006), está em curso um novo modelo econômico, com baixa taxa de expansão produtiva, forte vinculação à financeirização da riqueza e à revalorização do setor primário exportador. Neste contexto, a indústria estagnou ou regrediu sua oferta de empregos, o setor do agronegócio emprega

\footnotetext{
${ }^{1}$ A tese está presente, em maior ou menor grau, em autores como Giannotti (1990), Gorz (1982), Habermas (1987) e Offe (1989).

2 Para pesquisadores do Núcleo Interdisciplinar de Estudos e Pesquisas sobre Marx e o Marxismo (NIEP-Marx), Marcelo Dias Carcanholo e João Leonardo Medeiros, a ausência de estatísticas consolidadas a nível mundial impede-nos de retratar a amplitude do trabalho com mais precisão. Os números para a OCDE, no entanto, permitem, ao menos, caracterizar em linhas gerais o crescimento tanto da força de trabalho total quanto do nível de emprego. A força de trabalho total passou de 507.498 para 564.284 entre 1995 e 2006. 0 número de trabalhadores empregados, por sua vez, aumentou de 467.244 para 527.630, no mesmo período (www.ocde.org). Se, além dos países da OCDE, considera-se a China (estatísticas em www.ilo.org), o número de trabalhadores empregados passa de 1.147.894, em 1995, para 1.291.630, em 2006.
} 
pouca mão-de-obra - já que adota muita tecnologia produtiva - e o setor de serviços adota trabalho intermitente, informal e sazonal. Os efeitos sociais disso são perversos para um país como o Brasil com mais de $1 / 3$ da população vivendo na condição de extrema pobreza e a maioria com baixa escolaridade.

Metodologicamente, trata-se de um estudo qualitativo e quantitativo, ancorado em fontes bibliográficas e documentais, indicadores de economia e de mercado de trabalho, referenciado em pensadores da sociologia do trabalho e da educação contemporânea. Conceitualmente, esta reflexão implica em discernirmos e diferenciarmos as noções de emprego e trabalho, formação profissional e educação, no contexto histórico que ora atravessamos.

A educação concretiza-se por meio de processos educativos, sistematizados ou não, que se dão em diferentes espaços da vida cotidiana. A escola é uma instituição criada com o objetivo de socializar saberes e conhecimentos historicamente acumulados, mas também para construir outros. Desta forma, ela tem o papel de criar as condições para que o processo de ensino-aprendizagem dos estudantes se efetive. "O direito à educação é, em um sentido geral e por consequência, o direito de todas as pessoas se apropriarem da cultura, por essa apropriação ser parte essencial da condição humana e uma necessidade para o pleno usufruto da vida" (CARA, 2019).

\section{PERSPECTIVA DO EMPREGO}

Os primeiros indicadores das futuras relações emprego/profissão resultam de uma pesquisa realizada nos Estados Unidos, pela Secretaria Nacional do Trabalho, uma espécie de Ministério do Trabalho americano. Segundo esse estudo, o desemprego, no presente e no futuro, é produto das mudanças tecnológicas e da decadência mundial do setor industrial como carro-chefe das economias mais avançadas. Nessa ordem, a pesquisa americana enumera algumas profissões que se tornarão obsoletas no início deste século, contudo, alguns indicadores podem ser questionados no Brasil e em outros países em desenvolvimento. 0 estudo aponta, assim, para uma mudança significativa no emprego e nas profissões do futuro próximo.

A lista, em ordem decrescente, é a seguinte: fazendeiro; datilógrafo; digitador; revisor; guarda livros; contador e auditor; caixa de banco; costureira; faxineira e servente particulares; operador de computador; operador de xerox; operador e técnico de máquinas para indústria têxtil; escriturário; carregadores de materiais, estoque e carga; trabalhador rural; operador e técnico de máquinas de corte para plástico e metal; telefonista; instalador e técnico de PABX; montador elétrico e eletrônico; instalador e técnico de 
estações de informática; atendente de $\mathrm{RH}$, exceto os que se ocupam da folha de pagamento e horas trabalhadas, ademais, digitador de dados.

Esse é um estudo interessante e, como todo cenário futuro e estrangeiro, dependerá da continuidade de alguns fatores condicionantes que existem hoje. Sem embargo, é inevitável pensar, seriamente, no assunto. 0 futuro será sempre um grande desafio, principalmente àqueles que não se preocupam com ele ou que estejam precariamente aparelhados para enfrentá-lo; em especial crianças, jovens e adolescentes, além daqueles com mais de 40 anos.

Vivemos, nos dias de hoje, uma combinação explosiva. Por um lado, uma tímida atividade econômica nacional, marcada por um pequeno crescimento da atividade produtiva que beira à recessão e a necessidade das empresas tornarem-se cada vez mais enxutas e seletivas em suas contratações, buscando uma maior competitividade no mercado; por outro lado, a existência de um grande contingente de jovens sem experiência profissional, impossibilitados de pleitear as poucas vagas que se abrem.

A reunião desses e de outros fatores tem como resultado, aproximadamente, 13 milhões de desempregados, especialmente jovens na faixa etária entre 18 e 24 anos, sem ocupação profissional. De modo geral, a população economicamente ativa (PEA) configura-se da seguinte forma: um terço com emprego formal; um terço na economia informal e outro terço na condição de trabalhadores autônomos.

Paradoxalmente, o grande problema alegado para a contratação destes jovens, além da retração da atividade econômica, é a falta de experiência profissional. Sem acesso ao mercado de trabalho por falta de experiência, que nunca terão, grande parte deles permanecerá à margem do trabalho dito formal. Cria-se aí um grande dilema e gargalo social.

Uma das consequências do capitalismo financeiro contemporâneo, incapaz de assimilar o conjunto da força de trabalho, é o desemprego Juvenil no Mundo, conforme dados de dezembro de 2016 a janeiro de 2017, como outra evidência da dispensabilidade do mercado de trabalho. Vejamos, a título de exemplificação, as taxas de desemprego de jovens em alguns países: Argélia 29,9\%; União Europeia 18,6\%; Canadá 13,3\%; Finlândia 19,8; Espanha 42,9\%; Nigéria 25,0\%; Estados Unidos 10,1\%; África do Sul 54,2\%; França 26,2\%; Portugal 26,4\%; Itália 40,1\%; e Grécia 45,7\% (JOSUÉ, 2018).

Na sociedade brasileira, marcada pelo avanço de políticas neoliberais, que capturam e solapam, cada vez mais, direitos adquiridos pelos trabalhadores e ratificados pela Constituição Cidadã de 1988, 0 número de homens e mulheres em busca de emprego³ ultrapassa a casa dos 13 milhões. Em tal cenário,

\footnotetext{
${ }^{3}$ Cabe aqui assinalar que não entendemos trabalho como sinônimo de emprego.
} 
não é de admirar que as juventudes estejam entre os que mais têm sido penalizados com a volatidade, precariedade e informalidade do mercado de trabalho.

Entre 2014 e 2016, aumentou de $22,7 \%$ para $25,8 \%$ o percentual de jovens, entre 16 e 29 anos, sem trabalho (ocupação) e sem educação. Foram os jovens, também, os mais afetados pela crise a partir de 2008 , especialmente aqueles de cor preta ou parda $(29,1 \%)$ e, nesse grupo, as mulheres pretas e pardas foram as mais afetadas pelo fenômeno (37,6\%), de acordo com PNAD/IBGE 2017. A elevação da desocupação foi observada, ainda, em todos os grupos etários, tendência que se manteve em 2017. Já para as pessoas entre 14 e 29 anos de idade, a taxa de desocupação que era de 13,0\%, em 2014, aumentou ano após ano até alcançar 22,6\% em 2017, o aumento mais acentuado no triênio. A falta de oportunidades de emprego para os jovens é um desafio que se coloca em nivel internacional, compondo três metas da Agenda 2030 para os Objetivos de Desenvolvimento Sustentável - ODS, visto que a taxa de desocupação global das pessoas entre 15 e 24 anos era de 12,6\% em 2017. Na comparação internacional, a taxa de desocupação do Brasil de jovens nessa faixa etária, 28,0\%, posicionava o país entre as taxas mais expressivas observadas nos países da América Latina e Caribe (18,5\%) e do Nordeste da África (29,3\%) (IBGE, 2018).

São jovens brasileiros, portanto, as primeiras e maiores vítimas do desemprego, do trabalho informal e do temporário, da violência urbana e policial, das mortes de trânsito, do crime organizado e compõem, ainda, a maioria da população carcerária de um sistema prisional desumano e degradante. Na obra $A$ desconstrução do Futuro: juventudes, reforma do ensino médio e retrocessos das políticas educacionais (GRABOWSKI, 2019), tal realidade está evidenciada com dados estatísticos e análises das políticas para as Juventudes e educação no Brasil entre 2016 e 2018.

Não devemos pensar, simplesmente, que o problema está nos jovens e na sua inexperiência, mas, sim, refletir sobre dois fatos significativos: a falta de oportunidades e o subdesenvolvimento econômico. Os programas de estágio em empresas, as políticas públicas como o "Programa Primeiro Emprego", o estímulo ao empreendedorismo e a abertura de linha de microcrédito podem amenizar o problema, integrando uma parcela desses jovens ao mundo do trabalho. Estima-se que, de cada duas pessoas desempregadas no Brasil, uma seja jovem.

O problema é sério e atinge toda uma geração. Os reflexos são perversos e podem ser presenciados, diretamente, em nossas comunidades, através do aumento da criminalidade, consumo de drogas, desesperança, baixo poder de consumo, entre outros problemas sociais. Cabe-nos refletir e agir em busca de um crescimento econômico capaz de integrar os jovens ao mercado de trabalho, garantindo seu acesso e mantendo a empregabilidade dos que já estão trabalhando, especialmente as pessoas acima de 
45 anos. Não cremos em soluções mágicas, mas a retomada de uma atividade econômica considerável coadunada com políticas públicas permanentes e uma melhor qualificação dos jovens, através de processos educacionais de qualidade. Isso poderá garantir o pleno emprego; o que, hoje em dia, está cada vez mais difícil de encontrar.

\title{
3 NOVAS TECNOLOGIAS, FORMAÇÃO PROFISSIONAL E O EMPREGO
}

\begin{abstract}
Por isso a ameaça de perda de emprego não resulta apenas da ascensão da tecnologia da informação, mas de sua confluência com a biotecnologia. 0 caminho que vai do escâner de ressonância magnética ao mercado de trabalho é longo e tortuoso, mas ainda assim poderá ser percorrido em poucas décadas. 0 que os neurocientistas estão aprendendo hoje sobre a amígdala e o cerebelo pode permitir que computadores superem psiquiatras e guarda-costas humanos em 2050 (HARARI, 2018).
\end{abstract}

Uma das alternativas para alavancar a criação de novos postos de trabalho é a qualificação das pessoas, não somente nas atividades técnicas, mas, também, humanísticas. Não devemos perder de vista a formação integral do cidadão que se torna muito melhor preparado para as rápidas e constantes mudanças em nossa sociedade. Entretanto, hoje, em um plano muito particular e que possui uma tendência de continuidade nos próximos anos, a aposta parece ser muito dirigida à tecnologia.

A cada dia vem reforçando-se a tese que indica a tecnologia como um dos motores de desenvolvimento das sociedades. $\mathrm{O}$ marco deste movimento foi o relatório do IDH (Índice de Desenvolvimento Humano) e do IDT (Índice de Desenvolvimento Tecnológico), divulgado pela ONU. ${ }^{4}$

Dentro do conceito de tecnologia, a serviço da diminuição das desigualdades e da pobreza, destacase que a tecnologia de informação e de comunicação, além da biotecnologia, podem transformar-se em molas propulsoras do desenvolvimento e da erradicação da miséria.

\footnotetext{
${ }^{4}$ O ranking de 2018 do Índice de Desenvolvimento Humano (IDH), compilado pela ONU, traz o Brasil estagnado na $79^{a}$ posição.
} 
As tecnologias de informação e de comunicação seriam capazes de romper as barreiras geográficas, garantindo o acesso à educação de qualidade para um número maior de pessoas. Levariam, também, os programas de saúde pública e outras informações aos bolsões de extrema pobreza, em regiões como os conglomerados urbanos terceiro-mundistas. Por outro lado, a biotecnologia, por exemplo, ao mesmo tempo em que é capaz de refinar e tornar de altíssima qualidade produtos como o vinho, o queijo, a fruta e outros artigos de consumo seletos, proporciona um grande rendimento na agricultura voltada à alimentação humana.

O Brasil aparece em $43^{\circ}$ lugar, entre 72 países, no IDT e $73^{\circ}$ no IDH, porém, possui muitos centros de excelência. Somos o único país terceiro-mundista que possui dois pólos de inovação tecnológica reconhecidos internacionalmente, São Paulo e Campinas. Além disso, empenha-se em formar cerca de 5.000 doutores por ano e configura-se como $04^{\circ}$ país em número de incubadoras.

Para melhorarmos nosso desempenho, os desafios são muitos. Dentre eles, aumentar a taxa de inovação nas empresas, dar mais recursos para a implantação de empresas de tecnologia, capacitar melhor os técnicos e universitários, nas áreas de ciência e tecnologia, desenvolver as atividades industriais e de pesquisa aplicada e, sobretudo, romper as barreiras entre as Universidades, Centros de Pesquisa e as Empresas. Provavelmente resida aí a maior dificuldade cultural brasileira, isto é, o fato de universidades e empresas nem sempre trabalharem juntas e, quando o fazem, atuam de forma muito tímida.

O apoio dos empresários aos programas universitários e a entrada da universidade no "chão de fábrica" devem promover, em curto período, e a custos extremamente baixos, a transferência de tecnologia a processos específicos de cada setor ou atividade. Cabe ressaltar que o progresso da ciência e da tecnologia não é feito somente de máquinas e equipamentos; o componente humano é de fundamental importância e, talvez, seja o mais sensivel e o que precise de um maior tempo para se desenvolver.

0 entrave tecnológico não reside apenas em nossa capacidade de incorporar tecnologias prontas, mas na ineficácia em desenvolver, ao máximo, esses recursos através de nossos colaboradores. Assim, um bom começo para as empresas e universidades seria apoiar programas de educação à distância, empreendedorismo, criatividade, gestão tecnológica, design e outros que proporcionariam um ganho importante na qualificação do capital humano das empresas.

Até poucos anos, convivemos com a ideia de que era mais vantajoso copiar em vez de criar. Grande parte das empresas e universidades, preocupada em sobreviver, não desenvolveu uma cultura inovadora e um ambiente criativo. Esse quadro permaneceu inalterado até que começamos a experimentar uma estabilidade econômica e a conviver com o acirramento de uma competição internacional em busca da competitividade. Esta conjuntura alterou o equilíbrio das forças que passaram a pender para o lado 
daquelas empresas que possuíam melhores respostas tecnológicas, crescendo a necessidade de inovar e criar.

O surto de inovação encontrou o país, relativamente, organizado do ponto de vista científico e tecnológico, e com uma massa crítica de pesquisadores e centros de excelência qualificados. Apesar da produção científica brasileira crescer a cada ano, o país está, infinitamente, longe do desenvolvimento tecnológico de outras nações, mesmo em relação à Coreia, que se encontra em grau de desenvolvimento similar ao nosso. Segundo dados do Ministério de Ciência e Tecnologia, o Brasil depositou, no ano de 2000, 113 patentes de novos produtos nos Estados Unidos, enquanto a Coreia patenteou 3472 produtos ou processos inovadores.

A dificuldade em superar a distância entre universidades, centros de pesquisa e empresas emperra a transferência de tecnologia, deixando de atender os setores produtivos nacionais. Dessa forma, a inovação deixa de existir devido à falta de pesquisa e desenvolvimento, ensejando, no máximo, a importação de bens tecnologicamente avançados que se incorporam à produção, mas que aumentam nossa dependência tecnológica e intelectual. Nessa perspectiva, remetemos dólares e exportamos postos de trabalho com nosso baixo desenvolvimento tecnológico.

Precisamos, diante desse quadro, de alguns estímulos importantes, não somente ações de caráter nacional que coloquem essas questões como centrais em um processo de desenvolvimento regional sustentado e autônomo; mas, também, ações para mudar esta situação. Destacamos a criação de empresas de base tecnológica, a aproximação das universidades e empresas, com uma articulação das demandas empresariais e sociais com as competências acadêmicas.

Muitas outras ações podem ser tomadas, mas o desenvolvimento científico e tecnológico do país passa pelo fortalecimento da pesquisa e inovação. A sociedade tem se movimentado nesse sentido, cabe-nos apoiar e criar um ambiente de inovação e pesquisa, propício ao desenvolvimento regional, mas sem esquecer da formação integral das pessoas, sua visão humanística, seus valores em relação à humanidade e sua preparação para as contínuas transformações de nossa civilização.

As estratégias e alternativas de hoje vão ser questionadas no futuro e somente pessoas com uma visão global ampla e holística estarão, efetivamente, preparadas para as transformações e questionamentos.

Os avanços técnicos e científicos que experimentamos em profusão nos últimos anos do século XX não podem ser entendidos como uma prioridade dogmática pelas sociedades. Pelo contrário, devemos encará-los como produto de nossa cultura e das necessidades mercadológicas predominantes neste momento histórico, mas que, acima de tudo, expressam um conhecimento coletivo e internacionalizado.

Não devemos ter a ilusão de que somente o progresso tecnológico dará conta de melhorar as condições 
de vida da humanidade. Se isso fosse verdade, hoje, já, o conhecimento científico que possuímos poderia transformar, radicalmente, as condições de acesso à saúde, educação e alimentação do mundo contemporâneo.

Porque não fazemos essa transformação? O que nos falta conquistar? Que futuro nos espera? Três perguntas simples; todavia, de significação expressiva para nossa realidade e a toda humanidade. Primeiramente, não a fazemos porque aqueles que podem tomar as decisões, no panorama internacional, possuem outros critérios e prioridades que não necessariamente são o bem-estar da humanidade; sua lógica, regida pelo mercado livre, não se preocupa com o acesso às conquistas científicas e tecnológicas. Basta uma rápida olhada sobre a indústria farmacêutica, de software, de sementes, entre outras, para confirmar tais constatações.

Sobre o que nos falta conquistar, além de uma maior democratização do conhecimento, cabe, inclusive, um questionamento e uma reflexão sobre as lógicas de mercado e a racionalização econômica. Não deveria existir uma oposição da produção cultural, científica e tecnológica e o acesso a tais bens da humanidade. Esses avanços sempre nascem sob a luz do progresso e da democratização, mas muitos se transformam em ferramentas de concentração de poder e riqueza.

Por fim, o futuro que nos espera é aquele que estamos construindo hoje. Por isso, quanto antes iniciarmos a revalorização de uma visão e ação humanística das conquistas tecnológicas, tanto melhor. Seria um bom começo disso tudo, a real discussão sobre o homem como elemento central de nossa civilização, revendo os dogmas da ciência e da tecnologia como novas religiões.

Cabe-nos posicioná-los como conquistas da humanidade, valorizando as relações e a convivência humana em detrimento das ferramentas tecnológicas. Uma coisa é ter a ciência, tecnologia e inovação como esteios do crescimento econômico e do bem-estar social; outra é desconsiderar a cultura, a arte e as humanidades em geral, mães de nossa civilização.

Nossa civilização vai impor-nos, constantemente, adaptações e mudanças. Algumas relacionadas ao nosso trabalho; outras, às relações familiares ou, ainda, aos nossos valores culturais. Estarmos preparados para isso significa ter uma compreensão dos processos que a cada geração experimentamos; perceber, constantemente, um mundo que não pára de mudar e oferecer novas alternativas e soluções.

\section{CONSIDERAÇÕES FINAIS}

As transformações econômicas, científicas e tecnológicas impactam os sistemas de trabalho, produção, educação e formação profissional. Nada é imune às transformações em curso no mundo. As relações de emprego e os projetos de carreira profissional estão em profundas mudanças, deixando de ser trajetórias 
e carreiras profissionais estáveis e duradoras e configurando-se em relações intermitentes, temporárias e por demandas. Nesta perspectiva, não é o trabalho, enquanto relação de produção da sobrevivência humana, que está ameaçado, mas os empregos que estão em processo de precarização ou extinção.

Os sistemas educativos e de qualificação profissional já estão mudando em todo o mundo, voltandose para o desenvolvimento de competências e habilidades nos estudantes capazes de mobilizar conhecimentos para o saber fazer, de natureza criativa e inovadora, envolvendo novas estratégias e novas formações de relação social e profissional.

Neste contexto de mudanças na Educação, estamos enfrentando revoluções sem precedentes e todas as nossas narrativas e certezas estão ruindo. Como ninguém sabe qual será o aspecto do mundo em 2050 - muito menos em 2100 -, não temos propostas prontas nem modelos educacionais que nos deem alguma garantia.

Então, pergunta Yuval Harari, o que deveríamos estar ensinando? Muitos especialistas em educação alegam que as escolas e universidades deveriam passar a ensinar "os quatro Cs" - pensamento crítico, comunicação, colaboração e criatividade. Em um sentido mais amplo, as instituições formadoras deveriam minimizar habilidades técnicas e enfatizar habilidades para projetos genéricos na vida. 0 mais importante de tudo será a habilidade para lidar com mudanças, aprender coisas novas e preservar seu equilíbrio mental em situações que não Ihe são familiares. Para poder acompanhar o mundo em 2050, você vai precisar não só inventar novas ideias e produtos - acima de tudo, vai precisar reinventar a você mesmo várias e várias vezes. Nesse contexto, as humanidades têm que se posicionar com mais objetividade nessa sociedade contemporânea tecnológica. ${ }^{5}$

Como consequência, apesar do aparecimento de muitos novos empregos humanos, poderemos testemunhar o surgimento de uma nova classe de "inúteis". Estas novas oportunidades exigirão altos níveis de especialização e não resolverão, portanto, os problemas dos trabalhadores não qualificados que estão desempregados. A criação de novos empregos poderá mostrar-se mais fácil do que retreinar humanos para preencher esses empregos. Ademais, nenhum dos empregos humanos que sobrarem estará livre da ameaça da automação, uma vez que o aprendizado de máquina e a robótica continuarão a aprimorar-se. Se assim for, finaliza o pensador israelense, é possível que o mercado de trabalho em 2050 se caracterize pela cooperação, e não pela competição, entre humanos e a Inteligência Artificial.

Um mundo em mudanças com a aceleração do uso intensivo em tecnologia, com as novas formas de controle econômico e social e com a conexão humana exponencial é por nós habitado. Nessa nuvem,

\footnotetext{
${ }^{5}$ Ratto, Cleber Gibbon, 2017.
} 
o trabalho e a educação enfrentam, talvez, o seu maior desafio civilizatório. Certamente não temos um caminho ou resposta, mas, dessa discussão, nascerão os indicadores desse novo milênio, que esse artigo procurou explorar.

\section{REFERÊNCIAS}

CARA, Daniel. Contra a barbárie, o direito à educação. In: Educação contra a bárbarie: por escolas democráticas e pela liberdade de ensinar. Organização de Fernando Cássio. $1^{\text {a }}$ ed. - São Paulo: Boitempo, 2019.

GIANNOTTI, J.A. (1990). "Sociabilidade travada". Revista CEBRAP, número 28, outubro, São Paulo.

GORZ, A. (1982). Adeus ao proletariado: para além do socialismo. Forense Universitária, Rio de Janeiro. GRABOWSKI, Gabriel. A desconstrução do Futuro: juventudes, reforma do ensino médio e retrocessos das políticas educacionais. - Porto Alegre: Carta, 2019.

HABERMAS, J. (1987). Teoría de la acción comunicativa: crítica de la razón funcionalista. Taurus, Vol. 2, Madrid.

HARARI, Yuval Noah. 21 lições para o século 21. Tradução Paulo Geiger. - $1^{\text {a }}$ ed. - São Paulo: Companhia das Letras, 2018.

IBGE 2018 - Síntese dos Indicadores Sociais: Uma análise das condições de vida da população brasileira: - 2018/IBGE, Coordenação de População e Indicadores Sociais. Rio de Janeiro: IBGE, 2018.

PNAD/IBGE - Síntese dos indicadores sociais (SIS) - Rio de Janeiro, 2017. Disponivel em: <https:// agenciadenoticias.ibge.gov.br/agencia-sala-de-imprensa/2013-agencia-de-noticias/releases/18824sintese-dos-indicadores-sociais-um-em-cada-quatro-jovens-do-pais-nao-estava-ocupado-nemestudava-em-2016.html>. Acessado em: 06/01/2018.

POCHMANN, Márcio. Economia brasileira hoje: seus principais problemas. In: Fundamentos da educação escolar no Brasil contemporâneo. Organizado por Júlio César França Lima e Lúcia Maria W. Neves. Rio de Janeiro: Editora Fiocruz, 2006. 320 p., tab., graf.

RATTO, Cleber Gibbon. A importância das ciências humanas, letras e artes na sociedade tecnológica contemporânea. Revista Prâkis, v. 2 (2017): Língua, Literatura, Cultura e Ensino - Julho / Dezembro Dossiê. 